\title{
Improving Speaker's Use of Segmental and Suprasegmental Features of L2 Speech
}

\author{
Azza A. M. Abdelrahim \\ ${ }^{1}$ Assistant professor, Department of Languages and Translation, University of Tabuk, Tabuk, Saudi Arabia \\ Correspondence: Azza A. M. Abdelrahim, Department of Languages and Translation, University of Tabuk, \\ Tabuk, Saudi Arabia. E-mail: azza@ut.ed.sa
}

\author{
Received: June 10, $2020 \quad$ Accepted: July 13, $2020 \quad$ Online Published: July 17, 2020 \\ doi:10.5539/ijel.v10n5p203 URL: https://doi.org/10.5539/ijel.v10n5p203
}

\begin{abstract}
Unlike L1 acquisition, which is based on automatic acquisition, L2 adult learners' acquisition of English phonology is based on mental reflection and processing of information. There is a limited investigation of L2 phonology research exploring the contribution of the cognitive/theoretical part of pronunciation training. The study reports on the use of online collaborative reflection for improving students' use of English segmental and suprasegmental features of L2 speech. Ninety participants at the tertiary level at Tabuk university in the kingdom of Saudi Arabia were divided into two groups which used an online instruction. The only difference between the instruction of the experimental group and the control group is that the experimental group spent part of the time of instruction on collaborative reflection, while the control group spent this time on routine activities without using collaborative reflection (but all other activities were the same). The results showed that the online collaborative reflection improved the pronunciation of the experimental group. The learners learned the pronunciation of the major segmentals (e.g., vowels, consonants, diphthongs), minor segmentals (e.g., the way of articulation), and the suprasegmental features (e.g., intonation, stress). The results also showed that students perceived the online collaborative reflection as a helpful means in improving their use of L2 English phonology features. The findings have important implications and contribute to our theoretical knowledge of second language acquisition and L2 phonetics instruction research.
\end{abstract}

Keywords: L2 speech, Segmental features, Suprasegmental features, second language acquisition, processing of information, online collaborative reflection

\section{Introduction}

One of the important aspects of English speaking for ESL learners is pronunciation as it impacts on communication. According to Levis (2007), it plays a central role in speech perception and speaker identity. Incorrect pronunciation hinders the process of communication (Szpyra, 2014; Iandoli, 1990). In spite of the importance of pronunciation, some teaching approaches such as the cognitive movement and early communicative language ignored the acquisition and improvement of L2 pronunciation (Celce-Murcia, Brinton, \& Goodwin, 1996). Likewise, a great amount of L2 research neglected presenting tangible and explicit means for improving the acquisition of L2 English phonology. To our knowledge, much L2 research was conducted on measuring the impact of immersion of L2 learners in a target-language-speaking environment (e.g., Munro \& Derwing, 2008; Mora \& Valls-Ferrer, 2012; Towell, Hawkins, \& Bazergui, 1996) and others measured vocabulary size in relation to the improvement of L2 speech (Adolphs \& Schmitt, 2003, van Zeeland \& Schmitt, 2012; Bundgaard-Nielsen et al., 2011). I would argue that not all L2 learners have the opportunity to be immersed in L1 environment or have the opportunity to acquire a great amount of vocabulary to improve their L2 speech. L2 learners need to comprehend how to produce the correct sounds as, according (Granena \& Long, 2013), the acquisition of phonology is relatively difficult compared to the acquisition of vocabulary and grammar. The acquisition of L2 phonology is more difficult for L2 learners than the acquisition of L1 phonology for L1 learners. While L1 learners easily correlate the acquisition of L1 phonology to their existing L1 knowledge, L2 learners need to first correlate the acquisition of L2 phonology to their existing L1 knowledge, find similarities in their knowledge systems, and build upon their existing L1 knowledge.

Segmentals (e.g., consonants and vowels) and suprasegmentals (e.g., intonation patterns, stress placement, and rhythm in spoken language) are considered important features in the spoken English. They are critical in 
facilitating the meaning of speech and oral English communication. Among other factors, like L1 and L2 vocabulary, strategies, and memory load (Vandergrift \& Bakerm 2015), the listeners' perception and recognition of words and phrases rely on the speakers' correct use of segmentals and suprasegmentals. Their use is very important to recognize spoken words (Connell et al., 2018) and contrast the meaning (Ma, Zhou, Singh, \& Gao, 2017). However, the misuse of segmental and suprasegmental features can hinder the process of communication and the intelligibility of the meaning of spoken words. In spite of the importance of these features in speaking, many EFL students at Tabuk university misuse them in their speaking. Their misuse hinders the listeners' recognition of words (sound shapes) to retrieve their meaning from their mental lexicon. The study problem was empirically asserted by research (e.g., Rau, Chang, \& Tarone, 2009; Wu \& Saito, 2014) which showed L2 learners' difficulty in pronunciation of English segmentals and suprasegmentals in their speech.

Given the difficulty of L2 phonology acquisition for L2 learners and the necessary component of the cognitive/theoretical part of the pronunciation training, there is a limited investigation of L2 phonology research exploring the contribution of the cognitive/theoretical part of the pronunciation training. L2 phonology acquisition empirical research neglected the cognitive/theoretical part of the pronunciation training for processing information (e.g., using reflection) and creating of mental representations of the target L2 speech features. This study tries to fill the gap of the limitation of L2 empirical research exploring the contribution of the cognitive/theoretical part of the pronunciation training with help of technology to help teach L2 learners the use of speech features. One way suggested in this study for improving L2 learners' speech features at the tertiary level, in terms of the correct use of segmental and suprasegmental features, is through online collaborative reflection based on explicit instruction of L2 speech features. Reflection has been advocated by many theorists (e.g., Dewey, 1971; Freire, 1984) as it is closely related to learning and it helps learners to think back, process information, analyze and evaluate their experiences to plan for further action (Moon, 2013) for improving their lifelong learning (Rogers, 2001). "Collaborative reflection exceeds the exchange of individual experiences and insights in that it aims at the development of a shared understanding and transformation of collective knowledge practice" (Richter et al., 2012, p. 117). Learners have to learn to speak using the features of spoken English language as an important element among other elements that help in conveying the target meaning.

Some researchers have recommended focusing on learning only the suprasegmental features of spoken English (Derwing \& Rossiter, 2003; Warisara, 2013) and the others (e.g., Offerman \& Olson, 2016) have only focused on the use of segmental features. There is also a scarcity of empirical research investigating the acquisition of these features together or how to improve their use for second language learners (Veenendaal, Groen, \& Verhoeven, 2016). Research should focus on the suprasegmental features along with the segmental (Jenkins, 2004). The current study is the first study to investigate how to enhance the use of segmental and suprasegmental features via online collaborative reflection based on explicit instruction. Hence, this study aims at exploring whether online collaborative reflection could improve L2 learners' pronunciation in terms of their use of segmental and suprasegmental features. The study would contribute to explore the impact of collaborative reflection on using communicatively adequate speech features. It might contribute to a better understanding of how to construct an online collaborative learning environment for enhancing students' learning. Furthermore, the current study will provide potentially useful evidence on the relationship between reflection and language learning to contribute to the development of SLA research. Therefore, the current study tries to find answers for the following questions:

1) To what extent does the use of online collaborative reflection improve students' language learning in terms of the use of segmental features of speech?

2) To what extent did the use of online collaborative reflection improve students' language learning in terms of the use of suprasegmental features of speech?

3) What is students' perception of online collaborative reflection for improving their use of the segmental and suprasegmental features of speech?

\section{Literature Review}

\subsection{Reflective Learning}

John Dewey was one of the early proponents of reflective learning that focuses on experience and reflects on it by raising critical questions (Pawar \& Anscombe, 2014). Reflective learning is defined as the active and motivated mental process towards one's problem-solving activity. The process of reflection involves three steps: 1) a feeling of mental confusion and uncertainty, 2) using past experiences to resolve the given problem, and 3) search, explore, analyze, and experiment any possible means to solve the problem (Dewey, 1971). Other researchers consider reflective learning as mental and effective activities that require learners to move in a 
cyclical process starting from a problematic action, investigating to understand the underlying principles, moving to a theory, seeking alternatives, proposing an action plan, executing the plan, analyzing the plan, and evaluating it (Fullana et al., 2016; Park, 2011). Reflective learning typically applies to learning complex skills at a later stage in life. There is a clear connection between reflection and learning (Sugerman, 2000). Meaningful learning involves reflection (Moon, 2009). It is an essential part of the learning process and a key prerequisite for promoting students' learning and constructing learners' knowledge, meaning, personal skills, and reflective thinking (Fullana et al., 2016; Xie, Ke, \& Sharma, 2008). When learners are provided with opportunities to reflect upon their practices, they become active learners (Mezirow, 2008) and active thinkers. They identify, analyze, and solve the problems (Park, 2011) and consequently, learners feel the importance of their self in constructing their knowledge (Fullana et al., 2016) and have a self-perception of their progress.

Researchers used different means of reflection. Interviews-based on guided questions (Janssen, de Hullu, \& Tigelaar, 2008), reflective journals, logs, reflective diary, portfolios, scenarios in simulated spaces (Ryan \& Ryan, 2013), the use of incidental and anecdotal professional reflection (Tarrant, 2013), stimulated recall (Schmid, 2011) were previously used for promoting reflection. In addition, personal stories and pair/group co-operative discussions, blogs, electronic portfolios (Farr \& Riordan, 2015), written narratives and video-stimulated dialogues (Schmid, 2011), spoken reflection, group spoken reflection (Huang, 2010), and audiotaped journals (Dantas-Whitney, 2002) were also different means of reflection and were previously used for promoting reflection, deep thinking, and language learning. Furthermore, strategies such as peer assessment, self-correction, peer feedback (Xie et al., 2008) were used for assessing reflection levels, and promoting reflective learning process.

Some studies conducted in other disciplines have indicated the important role of reflection (Saito \& Miwa, 2007; Van den Boom, Paas, van Merriënboer, \& van Gog; 2004). They have demonstrated the critical role reflection plays in the learning process (Gotoda et al., 2013). One study was conducted on online reflection for enhancing English language learning in terms of enhancing learners' writing. Yang (2010) conducted a study on the use of online reflection for improving the learners' English writing skills. She used reflective journals on an online system with 95 undergraduate participants to arouse their reflection on both self-correction and peer review to improve their writing processes. The results showed that reflective journals on an online system helped students improve their writing processes. Furthermore, it helped them detect grammatical errors in their peer review and learn from each other.

\subsection{Segmental and Suprasegmental Features of Speech}

The segmental features of speech are discrete units that can be auditorily identified in the speech stream such as consonants and vowels (Crystal, 2015; Bauman-Waengler, 2008). While the suprasegmental features (also known as prosodic features) refer to "the phonetic and phonological aspects of spoken language that cannot necessarily be reduced to individual consonants and vowels but generally extend across several segments or syllables" (Fletcher, 2013, p. 523). They may extend over one syllable or one morpheme or one word (e.g., tone) and sometimes extend over longer stretches of utterance, like one phrase, or one clause, or one sentence (e.g., intonation) (Cruttenden, 1997). They include stress, pitch, length, intonation (Fox, 2000), awareness of speech, rhythm, and word boundaries (Veenendaal, Groen, \& Verhoeven, 2016). While segmentals (vowels and consonants) are important for achieving accuracy in pronunciation and they should be learned (Munro \& Derwing 2006), suprasegmental (prosodic) features have an important role in clarifying and comprehending meanings in English. According to Connell et al. (2018), spoken words recognition is influenced by suprasegmental features. Intonation (Yenkimaleki, \& van Heuven, 2018) for example may convey several meanings. It may mean a discoursal meaning, for instance, it may be used to turn a statement into a question.

There are some studies that have examined the acquisition of L2 phonological features. On the one side, the face to face-based studies, there is for instance the longitudinal study of Bundgaard-Nielsen et al. (2011) which explored the relationship between vocabulary growth and the development of phonological behavior of Japanese learners of English. The results showed that L2 English vowel identification patterns did not significantly change and vowel perception was strongly predicted by their vocabulary size. Further, the studies of Flege et al. (1997), Munro and Derwing (2008), and Derwing et al. (2009) examined the effect of immersion in L1 English-language experience on non-native speakers' production and perception of English vowels and fluency. The results showed that experienced L2 learners demonstrated better improvement in their vowels use and fluency. Moreover, Offerman and Olson (2016) investigated the use of a classroom-based visual feedback for segmental feature instruction, namely voice onset time, which has been shown to be a distinctive marker of foreign accent for English L2 learners of Spanish. One the other side, the technology-based studies of L2 phonological acquisition, for instance, Warisara (2013) investigated the effectiveness of an e-learning program on improving 
the use of stress and intonation in the pronunciation of English by Thai learners in higher education. The findings showed that students' pronunciation improved after they used the online learning program. Further, Yenkimaleki and Van Heuven (2019) conducted an experimental study to compare the impact of technology vs. face to face instruction on prosody teaching for developing L2 learners' speaking skills. The results showed that the experimental group, which used computer assisted prosody training without using explicit instruction, was developed in speaking skills. Given the above literature, it is obvious that the studies conducted for developing both the segmental and suprasegmental features of English phonology with focusing on the necessary component of the cognitive part of pronunciation in terms of using explicit instruction for processing information (e.g., using online collaborative reflection) for facilitating the acquisition of English segmentals and prosody for L2 leaners, in higher education, are scarce. This conclusion is also supported by Veenendaal (2016) who pointed out that studies of investigating L2 English phonology features are scarce.

\section{Methods}

This study followed the Pretest- posttest control group design. The independent variable is the online collaborative reflection using reflective videos on LMS while the dependent variable is students' progress in terms of their improvement in the pronunciation of segmental and suprasegmental features of speech.

\subsection{Context of Study and Participants}

The current study aims at developing students' pronunciation of segmental and suprasegmental features of English through online collaborative reflection. Collaborative reflection involves students' analysis and reflection on their own and their peers' practices of the use of English features towards the advancement of their cognitive knowledge practices of English features through their online learning. It exceeds the individual exchange of knowledge related to features of English. The analysis and reflection of English features are carried out by the students in collaboration with their teacher as an expert and a guide for them. Online collaborative exceeds the one-way exchange of individual practice of knowledge from one student towards the development of a shared understanding of collective knowledge of features of English.

The current study was conducted in a public university in Kingdom of Saudi Arabia, namely University of Tabuk. Participants of the current study were learners enrolled in a 14-week, credit-bearing online course entitled phonetics. One of the course requirements for students was to demonstrate the theoretical information and transcriptions of the English features and accompanied with explicit instruction of the way of articulation of these features using the correct pronunciation of segmental and prosodic features of English.

Ninety university female students enrolled in the English phonetics course accepted to participate in the current study. They were native speakers of Arabic and they were in the first year of languages and translation academic major. The average age of the participants was 19 years. They had studied English for seven years and they were at the intermediate level of the general English proficiency test. They took a placement test of English proficiency (i.e., Cambridge English Placement Test: computer-adaptive subtests of English Listening and Reading Proficiency) and it was found that there was no significant difference in the level of English proficiency between the experimental group and the control one after. 45 participants were assigned to the experimental group while the remaining 45 students were assigned to the control group. Prior to the study, all participants had signed a form of consent to participate in the study and filled a form about their personal information (e.g., name, age, gender, and years of studying English).

\subsection{Instruments}

The researcher constructed two tests; segmental features test and suprasegmental features test to assess students' use of them before and after the intervention. They were administered twice, i.e. at the beginning and one at the end of the study. The segmental features test (see Supplementary File: Appendix B) consisted of two parts; part one dealt with students' perception of segmental features (choosing the words they heard) and part two dealt with students' production of segmental features (reading given words). The prosodic features test (see Supplementary File: Appendix C) consisted of five parts; part one dealt with students' perception of prosodic features (underline the stressed syllables in words that they heard) and parts two to five dealt with students' production of prosodic features. The tests were validated by professors specialized in phonetics before they were used in the study and their amendments were considered in the final version. Further, for achieving content validity, the test items were also constructed based on reviewing literature related to segmental and suprasegmental features including (Connell et al., 2018; Fox, 2000; Szpyra, 2014) (see A ppendices A\&B).

The study used an analytical scoring schemes for assessing students' segmental and suprasegmental features in their pronunciation in reading. It was administered twice, i.e. at the beginning and at one the end of the study. 
The scoring rubric had a score range from 1-4. It was validated by professors specialized in assessment and phonetics before it was used in the study. It was also validated by content validation based on reviewing literature related to the assessment of segmental and prosodic features (see Appendix D). The study also prepared an online questionnaire for students in the experimental group. It was conducted online at the end of the semester. It was designed to investigate students' perception of using reflective videos on LMS for improving their English learning. Students' responses were ratings on a five-point Likert scale $(1=$ strongly disagree, $2=$ disagree, 3 = neutral, $4=$ agree, $5=$ strongly disagree). The questionnaire included five questions (see Supplementary File: Appendix E) with a fixed response.

\subsection{Procedures}

Before the intervention, participants were randomly assigned to a control group and an experimental one. To ensure the equivalence between the control group and the experimental one, pre-tests on the segmental and prosodic features were conducted to assess their level before the intervention. Both the groups took the same course, the same content, the same instructional materials, and the same assignments. However, only the experimental group was asked to construct reflective videos following the framework (see Table 1), created by Chau and Cheng (2012), for applying reflection in their videos and submit them on LMS. The control group did not create reflective videos and they accomplished routine spoken and written activities related to these features instead. Students were also encouraged to keep in regular contact with the teacher.

At the beginning of the intervention, a model of the reflective videos was presented to the experimental group. After receiving explicit instruction on the use of segmentals and suprasegmentals features, students of the experimental group were told to create reflective videos in which they had to reflect on their L2 English phonology learning. In their reflective video, they had to apply the correct use of segmental (e.g., interdental fricative; diphthongs; short vowel; long vowel) and suprasegmental features (e.g., stressed syllables, intonation, reduction and contraction) in their pronunciation while narrating their reflection on their L2 learning experiences. These reflective videos were submitted on LMS for the teacher to display them for receiving a collaborative reflection on their pronunciation from both the teacher and the peers (see Appendix A: Layout of a sample of the content of reflective videos). The 45 experimental groups' accuracy was assessed by the researcher and a native English speaker volunteer as an assistant listener to attempt to identify which vowels had been spoken, and through using rubrics (see Appendix D) for examining learners' pronunciation concerning the use of use of the segmental and suprasegmental features. On the other hand, participants of the control group had no access to watch or read the experimental group's videos and reflective comments. At the end of the intervention, the first reflective videos on the fourth week and the last reflective videos were analyzed by the researcher and another volunteer native English speaker teacher to show how the current intervention contributed in improving students' learning in terms of the use of segmental and suprasegmental features in English speech.

Table 1. A four-level framework for reflective L2 learning classification

\begin{tabular}{ll}
\hline Elements of reflection & Description \\
\hline Analysis, reformulation and & The ability to analyze, reformulate, and refocus the experience; comprehensive discussion of \\
future application & implications of the experience in the context of future applications \\
Strategy application & To analyze effectiveness of applied or alternative strategies for language learning \\
External influences & To make comments on external influences, (e.g. circumstances, others' perspectives) on the experience \\
Report of events or experiences & to report significant aspects of events or experiences \\
\hline
\end{tabular}

\subsection{Data Analysis}

In the current study, the statistical data analysis was carried out using SPSS Version 22 for Windows. T-test for independent samples was used for the quantitative data to answer the first and second research questions. A volunteer native English-speaking listener, the researcher and the use of the analytical scoring rubrics were the means of assessing the segmental and suprasegmental features in learners' speech. The internal reliability between the two researchers was 0.88 . Cronbach's alpha coefficient was also used to test the reliability of the instruments of the current study. The alpha coefficients of reliability were $0.88,0.87$, and 0.86 for segmental features test, prosodic features test, and the questionnaire respectively. Students' perceptions on the questionnaire, on how they think about the online collaborative reflection for language learning, were analyzed using descriptive statistical analysis. 


\section{Results}

Before the intervention, the ninety participants' data (45 students used online collaborative reflection and 45 students without using online collaborative reflection) have been collected and analyzed in the current study. Table 2 shows that there were no significant differences $(p>0.05)$ in the mean scores of the control group and the experimental group in the English proficiency test $(\mathrm{Mc}=32.300, \mathrm{Me}=31.766, \mathrm{p}=.634)$ so the two groups were homogeneous at the beginning of the intervention. Table 3 also shows that there were no significant differences $((p>0.05)$ in the mean scores of the control group and experimental group in the pretest of segmental features test $(\mathrm{Mc}=12.166, \mathrm{Me}=11.866, \mathrm{p}=.655)$, so the two groups were homogeneous at the beginning of the intervention. Table 4 also shows that there were no significant differences $(p>0.05)$ in the mean scores of the control group and experimental group in the pretest of prosodic features test $(\mathrm{Mc}=11.866$, $\mathrm{Me}=12.333, \mathrm{p}=.466$ ), so the two groups were also homogeneous at the beginning of the intervention.

Table 2. Mean scores of the English proficiency pre-test

\begin{tabular}{lllllll}
\hline Group & $\mathrm{N}$ & $\mathrm{M}$ & $\mathrm{SD}$ & $\mathrm{T}$ & $\mathrm{df}$ & $\mathrm{p}$ \\
\hline Control & 45 & 32.3000 & 6.22543 & 0.478 & 88 & 0.634 \\
Experimental & 45 & 31.7667 & 5.99538 & & & \\
\hline
\end{tabular}

Table 3. Mean scores of the segmental features pre-test

\begin{tabular}{lllllll}
\hline Group & $\mathrm{N}$ & $\mathrm{M}$ & $\mathrm{SD}$ & $\mathrm{T}$ & $\mathrm{df}$ & $\mathrm{p}$ \\
\hline Control & 45 & 12.166 & 2.755 & 0.457 & 88 & 0.650 \\
Experimental & 45 & 11.866 & 2.315 & & & \\
\hline
\end{tabular}

Table 4. Mean scores of the prosodic features pre-test

\begin{tabular}{lllllll}
\hline Group & $\mathrm{N}$ & $\mathrm{M}$ & $\mathrm{SD}$ & $\mathrm{T}$ & $\mathrm{df}$ & $\mathrm{p}$ \\
\hline Control & 45 & 11.866 & 2.315 & 0.715 & 88 & 0.477 \\
Experimental & 45 & 12.333 & 2.720 & & & \\
\hline
\end{tabular}

After the intervention, the current study could find the answer to the study questions as following:

FQ1: To what extent did the use of online collaborative reflection enhance students' language learning in terms of the use of segmental features of speech?

This question was addressed by using segmental features achievement test to compare between the scores of the experimental group (which used collaborative reflection) and the control group (which did not use collaborative reflection) in an online instruction. T-test results are shown in Table 5. Results from the segmental features test revealed that students of the experimental group who used online collaborative reflection outperformed students of the control group who did not use online collaborative reflection. The findings indicated that there were significant differences between the scores of the two groups $(\mathrm{Mc}=18.15, \mathrm{Me}=20.20, \mathrm{p}=.001)$ (see Table 5). In addition, Cohen's effect size was calculated and its value was $(\mathrm{d}=1.0)$ which indicated a high significance. According to Cohen (1997), the effect size is classified as follows: The 0.2 effect size indicates "small effect", the 0.50 effect size indicates "medium", and the effect size of 0.80 and more than that, indicates a large effect size. Thus, in this study, the difference between these two groups represents a high effect size.

Table 5. T-test of the segmental features post-test

\begin{tabular}{lllllll}
\hline Group & $\mathrm{N}$ & $\mathrm{M}$ & $\mathrm{SD}$ & $\mathrm{T}$ & $\mathrm{df}$ & $\mathrm{p}$ \\
\hline Control & 45 & 18.15 & 1.91 & 3.56 & 88 & .001 \\
Experimental & 45 & 20.20 & 1.99 & & & \\
\hline
\end{tabular}

Note. $p<0.001$.

To further examine if there were significant differences in scores for each group independently before and after the intervention, a t-test for paired samples was performed for each group. The results for the experimental group' performance before and after the intervention indicated that there were significant differences between the scores of the experimental group in the pre-test and the post-test of segmental features (pre-Me $=12.33$, post-Me $=$ $20.20, \mathrm{p}=.000$ ) (as shown in Table 6). For the control group, the results of t-test for paired samples listed in 
Table 7 further show that there were significant differences in the scores of the control group in the pre-test and the post-test of segmental features (Pre-Mc $=12.17$, Post-Mc $=18.15, \mathrm{p}=.001$ ) (as shown in Table 7). The results indicate that the experimental group which used online collaborative reflection showed more improvement in learning in terms of the use of segmental features of English speech than the control group which did not use collaborative reflection.

Table 6. T-test of the pre-test and post-test of segmental features of the experimental group

\begin{tabular}{lllllll}
\hline Experimental Group & $\mathrm{N}$ & $\mathrm{M}$ & $\mathrm{SD}$ & $\mathrm{T}$ & $\mathrm{df}$ & $\mathrm{p}$ \\
\hline pretest & 45 & 12.33 & 2.72 & 15.45 & 44 & .000 \\
posttest & & 20.20 & 1.91 & & & \\
\hline
\end{tabular}

Note. $\mathrm{p}<0.001$

Table 7. T-test of the pre-test and post-test of segmental features of the control group

\begin{tabular}{lllllll}
\hline Control Group & $\mathrm{N}$ & $\mathrm{M}$ & $\mathrm{SD}$ & $\mathrm{T}$ & $\mathrm{df}$ & $\mathrm{p}$ \\
\hline pretest & 45 & 12.17 & 2.31 & 11.6 & 44 & .000 \\
posttest & & 18.15 & 1.99 & & & \\
\hline
\end{tabular}

Note. $\mathrm{p}<0.001$.

FQ2-To what extent did the use of online collaborative reflection enhance students' language learning in terms of the use of suprasegmental features of speech?

This question was addressed by using a suprasegmental features achievement test to compare between the scores of the experimental group (which used online collaborative reflection) and the control group (which did not use online collaborative reflection). T-test results are shown in Table 8. Results from the suprasegmental features test revealed that students of the experimental group who used online collaborative reflection outperformed students of the control group who did not use online collaborative reflection. The findings indicated that there were significant differences between the scores of the two groups $(\mathrm{Mc}=19.00, \mathrm{Me}=22.96, \mathrm{p}=.000)($ see Table 8$)$.

Table 8. T-test of the suprasegmental features posttest between the control group and the experimental group

\begin{tabular}{lllllll}
\hline Group & $\mathrm{N}$ & $\mathrm{M}$ & $\mathrm{SD}$ & $\mathrm{T}$ & $\mathrm{df}$ & $\mathrm{p}$ \\
\hline Control & 45 & 16.56 & 3.07 & 7.59 & 88 & .000 \\
Experimental & 45 & 22.96 & 3.44 & & & \\
\hline
\end{tabular}

Note. $p<0.001$.

To further examine if there were significant differences in scores for each group independently before and after the intervention, a t-test for paired samples was performed for each group. The results for the experimental group' performance before and after the intervention indicated that there were significant differences between the scores of the experimental group in the pre-test and the post-test of suprasegmental features (pre-Me $=12.33$, post-Me $=22.96, p=.000$ ) (as shown in Table 9). For the control group, the results of t-test for paired samples listed in Table 10 further show that there were significant differences in the scores of the control group in the pre-test and the post-test of segmental features (Pre-Mc $=11.86$, Post-Mc $=16.36, \mathrm{p}=.000$ ). The results indicate that the experimental group's use of online collaborative reflection can increasingly improve students' online learning performance in terms of the use of suprasegmental features of English speech.

Table 9. Results of suprasegmental features test of the experimental group

\begin{tabular}{lllllll}
\hline Experimental Group & $\mathrm{N}$ & $\mathrm{M}$ & $\mathrm{SD}$ & $\mathrm{T}$ & $\mathrm{df}$ & $\mathrm{p}$ \\
\hline pretest & 45 & 12.33 & 2.72 & 11.46 & 44 & .000 \\
posttest & & 22.96 & 3.44 & & & \\
\hline
\end{tabular}

Note. $p<0.001$. 
Table 10. Results of suprasegmental features test of the control group

\begin{tabular}{lllllll}
\hline Control Group & $\mathrm{N}$ & $\mathrm{M}$ & $\mathrm{SD}$ & $\mathrm{T}$ & $\mathrm{df}$ & $\mathrm{p}$ \\
\hline pretest & 45 & 11.86 & 2.70 & 5.24 & 44 & .000 \\
posttest & & 16.56 & 3.07 & & & \\
\hline
\end{tabular}

Note. $p<0.001$.

FQ3- What is students' perception of online collaborative reflection for improving their use of the segmental and suprasegmental features of speech?

To answer this question, data were collected from the online questionnaire conducted on only the participants of the experimental group. The response rate achieved from the online questionnaire was very high (See Appendix F). The results of students' responses show that $77.8 \%$ of the responses strongly agreed and $22.2 \%$ of respondents agreed that online collaborative reflection helped them improve their English learning in terms of their pronunciation. A high proportion of respondents (71.1\%) strongly agreed that the online collaborative reflection improved their use of segmental features of English speech and $28.9 \%$ of respondents agreed on that item. A similar proportion of respondents $(62.2 \%)$ strongly agreed and $(31.1 \%)$ respondents agreed that the online collaborative reflection could help them improve their use of suprasegmental features of English speech. Over half $(55.6 \%)$ respondents strongly agreed and $(33.3 \%)$ agreed and $(11 \%)$ were neutral that the online collaborative reflection facilitated their reflective learning. Similarly, two thirds of $(82.2 \%)$ respondents strongly agreed and (17.8\%) respondents agreed that the online instruction facilitated their online collaborative reflection which helped them improve their English features.

\section{Discussion}

The study predicted that online collaborative reflection would cause considerable improvement in pronunciation in terms of L2 learners' use of English segmental and suprasegmental features of speech. With regard to the study results, it is found that allowing L2 learners to reflect collaboratively on their pronunciation had an effect on improving their use of the English segmental and suprasegmental features. With respect to the improvement in segmental features, the exchanging of reflection among learners via interactive and synchronous environment resulted in a significant improvement in the pronunciation of the experimental group in terms of the use of segmental features (consonants and vowels). The experimental group who used online collaborative reflection outperformed students of the control group who did not use online collaborative reflection. The learners of the experimental group were able to produce correct vowels and consonants. They learned the pronunciation of the major segmental (e.g., vowels, consonants, diphthongs) and minor segmentals (e.g., the way of articulation). These findings complement the study of Schmid (2011) and Dantas-Whitney (2002) who found that reflection is a powerful teaching and learning tool in enhancing students' learning. Further, it helps students learn to critique their own work and the work of others.

The second research question addressed the effect of online collaborative reflection in improving the pronunciation of L2 learners in terms of their use of English suprasegmental features of speech. The experimental group outperformed the control group. The use of collaborative reflection helped them improve their pronunciation in terms of the use of suprasegmental features (e.g., intonation, stress, and syllable). They became aware of the way of sound articulation and the cases in which they can use correct suprasegmentals features including fall intonation, rise intonation, fall-rise intonation. They became capable of identifying stressed syllables and using contraction and reductions correctly. Thus, the exchange of reflection collaboratively with L2 learners provided an opportunity for the experimental group to improve their pronunciation in terms of the use of suprasegmentals. These findings complement the findings of the studies conducted by Warisara (2013) and Yenkimaleki and Van Heuven (2019) which found that technology can participate in improving students' pronunciation and speaking.

The third research question addressed L2 students' perception of the online collaborative reflection for improving their use of the segmental and suprasegmental features of speech. The participants of the experimental group pointed out that online collaborative reflection helped them in their language learning in terms of improving their pronunciation of segmental and suprasegmental features of speech. The findings indicated online instruction facilitated students' online collaborative reflection provided with opportunities to reflect upon their practices and active thinkers. They were also able to identify and analyze incorrect pronunciation. Collaborative reflection, which exceeds the individual exchange of practices and experiences, helped them develop a shared understanding of their use of L2 phonology features. These findings compliment the study of Dantas-Whitney (2002) which showed that using reflection in a second language enables learners to be critical thinkers through 
analyzing and examining their learning processes. Furthermore, it showed that reflection is a valuable opportunity for oral language practice.

\section{Conclusions}

The purpose of the current study was three-fold. First, it was conducted to investigate the effect of online collaborative reflection on improving students' English learning in terms of improving their use of L2 segmental and suprasegmental features of speech. Second, it explored university students' perception of using online collaborative reflection to support their language learning. The results from data analysis indicate that the use of online collaborative reflection could significantly improve L2 learners' use of segmental and suprasegmental features and positive attitude towards the use of online collaborative reflection.

In this study, students' improvement in the use of segmental and prosodic features was significantly correlated to collaborative reflection. The findings of the current study showed that collaborative reflection enables learners to comprehend the phonology content, recognize and discriminate their mispronunciation and misuse of speech features to reflect on and use them correctly. They could collaboratively share their reflective videos with their peers for exchanging their reflection and thoughts on the learning process and the learning objectives they achieved. This study has also concluded that when L2 learners use language in a relevant context and natural settings (e.g., reflect on their experience) based on technology, they tend to demonstrate the fast acquisition of intended learning outcomes (e.g., producing correct features of L2 speech) and improve their phonology learning. The study demonstrated that L2 learners' English segmentals and suprasegmentals have been improved as a result of the development of their L2 phonology system. This means that there is a strong correlation between the development of learners' phonology systems and the improvement in learning L2 speech features. This development in L2 phonology system and the improvement in L2 speech features were due to collaborative reflection based on technology.

While the study gives insight into the improvement of students' learning of L2 speech when using online collaborative reflection, there are some limitations that future research can address. First, while the research design was a pretest and posttest quasi-experimental focusing on the use of online collaborative reflection in a single institution and it was conducted on one gender (i.e., females) only because of restrictions related to the nature of society in which there is no mix of gender, the findings cannot be widely generalized to other participants. Future studies exploring the improvement of students' pronunciation by using online collaborative reflection with male participants and in other settings, like in face-to-face classes as opposed to on-line are required to support or refute the results of the current study. Second, the current study focused only some features of suprasegmental features (e.g., stress, intonation, reduction and contraction, length of the syllable), future research capturing other features of suprasegmental such as pitch pattern, rhythm and loudness of speech need to be conducted. Third, conducting longitudinal data collection in the current study might help to shed light on how the current study might influence the critical learning of language in terms of developing critical discourse analysis. Moreover, further research is needed to conduct a longitudinal study of other segmental and suprasegmental features which were handled in this study. Finally, in this study, online collaborative reflection was supported by Learning Management Systems to improve learners' learning. It is recommended that using online collaborative reflection as an instrument for learners' learning and evaluation, in terms of evaluating and learning learners' pronunciation, will be beneficial.

The study offers theoretical and pedagogical implications for L2 English phonology research. Theoretically, it gives insights into the acquisition of learners' L2 English phonology that contribute to the theoretical knowledge in SLA. Unlike L1 acquisition, which is based on automatic natural acquisition, L2 adult learners' acquisition of English phonology is based on mental identifications (reflection) and processing of information of the acquired knowledge to correlate it with their existing knowledge and build the new information. L2 adult learners can attain segmental and suprasegmental competence in English speech as they become more capable of collaboratively reflecting on their L2 input and output. Hence, L2 adult learners' perception and production of L2 phonology features does not occur automatically but their occurrence depends on processing and reflecting on information. Pedagogically, to keep students at the same level of participation during the implementation of online collaborative reflection, they should be incentivized. Teachers should provide extrinsic motivators and positive reinforcement for avoiding learners' boredom and shyness. They may also need to control the irrelativeness of some peer reflective comments and feedback, and it is important for teachers to allow the related peer reflective comments and feedback in future practice of the same intervention. Further, it should be taken into consideration students' recordings accompanied by the video slideshows. Recordings should be pure enough and recorded away from their daily routines and disturbances. In addition, the researcher's examination of students' pronunciation relied only on using rubrics which consumes much time and causes a heavy burden on 
the researcher. However, it is suggested that the use of speech analysis equipment/software will decrease the burden on the researcher. Finally, it is important for teachers of second language phonology to develop their pedagogical practices of features of English speech to improve their L2 speakers' pronunciation. Higher education institutions' Stakeholders should provide teachers of phonology with professional development programs on cognitive and theoretical trainings of pronunciation accompanied by using interactive learning environment for developing their old practices of phonology instruction. According to Abdelrahim (2020), such programs of professional development trainings are considered powerful learning means for developing teacher educationally and professionally.

\section{Acknowledgements}

The authors would like to thank the reviewers and the editors for their insightful comments on this article. This research did not receive any specific grant from funding agencies in the public, commercial, or not-for-profit sectors.

\section{References}

Abdelrahim, A., \& Abdelrahim, M. (2020). Teaching and Assessing Metadiscoursal Features in Argumentative Writing: A Professional Development Training for EFL Teachers. IJAL International Journal of Applied Linguistics, 30(1), 70-91. https://doi.org/10.1111/ijal.12264

Adolphs, S., \& Schmitt, N. (2003). Lexical Coverage of Spoken Discourse. Applied Linguistics, 24(4), 425-438. https://doi.org/10.1093/applin/24.4.425

Bauman-Waengler, J. (2008). Introduction to Phonetics and Phonology: From Concepts to Transcription. London: Pearson.

Bundgaard-Nielsen, R., Best, C., \& Tyler, M. (2011). Vocabulary size is associated with second language vowel perception performance in adult learners. Studies in Second Language Acquisition, 33(3), 433-461. https://doi.org/10.1017/S0272263111000040

Celce-Murcia, M., Brinton, D., \& Goodwin, J. (1996). Teaching pronunciation: A reference for learners of English to speakers of other languages. Cambridge, England: Cam-bridge University Press.

Chau, J., \& Cheng, G. (2012). Developing Chinese students' reflective second language learning skills in higher education. The Journal of Language Teaching and Learning, 2(1), 15-32.

Cohen, J. (1997). Statistical power analysis for the behavioural sciences (2nd ed.). New Jersey: Lawrence Erlbaum Associates.

Connell, K., Huls, S., Shin, S., Tremblay, A., Martinez-Garcia, M. T., Qin, Z., \& Yan, H. (2018). English Learners Use of Segmental and Suprasegmental Cues to Stress in Lexical Access: An Eye-Tracking Study. Language Learning, 68(3), 635-668. https://doi.org/10.1111/lang.12288

Crystal, D. (2015). A dictionary of linguistics and phonetics (6th ed.). Malden, MA: Blackwell.

Dantas-Whitney, M. (2002). Critical reflection in the second language classroom through audiotaped journals. System, 30(4), 543-555. https://doi.org/10.1016/S0346-251X(02)00046-5

Derwing, T. M., Munro, M. M., Thomson, R. I., \& Rossiter, M. J. (2009). The relationship between L1 fluency and L2 fluency development. Studies in Second Language Acquisition, 31(4), 533-557. https://doi.org/10.1017/S0272263109990015

Derwing, T. M., \& Rossiter, M. J. (2003). The Effects of Pronunciation Instruction on the Accuracy, Fluency, and Complexity of L2 Accented Speech. Applied Language Learning, 13, 1-18.

Dewey, J. (1971). How We Think: A Restatement of the Relation of Reflective Thinking to the Educative Process. Boston: D.C. Heath \& Co Publishers.

Farr, F., \& Riordan, E. (2015). Tracing the Reflective Practices of Student Teachers in Online Modes. ReCALL, 27(1), 104-123. https://doi.org/10.1017/S0958344014000299

Flege, J., Bohn, O.-S., \& Jang, S. (1997). The effect of experience on nonnative subjects' production and perception of English vowels. Journal of Phonetics, 25(4), 437-470. https://doi.org/10.1006/jpho.1997.0052

Fletcher, J. (2013). The Prosody of Speech: Timing and Rhythm. In W. J. Hardcastle, J. Laver \& F. E. Gibbon (Eds.), The handbook of phonetic sciences (pp. 523-602). Hoboken: Wiley-Blackwell.

Fox, A. (2000). Prosodic features and prosodic structure: The phonology of suprasegmentals. Oxford, UK: 
Oxford University Press.

Freire, P. (1984). The politics of education: culture, power, and liberation. Hadley, Mass: Bergin \& Garvey.

Gotoda, N., Sakurai, Y., Nakagawa, K., Miyaji, C., \& Matsuura, K. (2013). A server-based system supporting motor learning through real-time and reflective learning activities human-computer interaction. In M. Kurosu (Ed.), Human-Computer Interaction: Applications and Services (pp. 84-93). 15th International Conference, HCI International 2013, Las Vegas, NV, USA, July 21-26, 2013, Proceedings, Part II. Berlin Heidelberg: Springer. https://doi.org/10.1007/978-3-642-39262-7_10

Granena, G., \& Long, M. H. (2013). Age of onset, length of residence, language aptitude, and ultimate L2 attainment in three linguistic domains. Second Language Research, 29, 311-343. https://doi.org/10.1177/0267658312461497

Huang, L.-S. (2010). Do different modalities of reflection matter? An exploration of adult second-language learners' reported strategy use and oral language production. System, 38(2), 245-261. https://doi.org/10.1016/j.system.2010.03.005

Iandoli, L. J. (1990). How can the language teacher help students to approximate native pronunciation, intonation, and body language? Language Quarterly, 28(1-2), 22-31.

Janssen, F., de Hullu, E., \& Tigelaar, D. (2008). Positive experiences as input for reflection by student teachers. Teachers and Teaching, 14(2), 115-127. https://doi.org/10.1080/13540600801965903

Jenkins, J. (2004). Research in teaching pronunciation and intonation. Annual Review of Applied Linguistics, 24(1), 109-125. https://doi.org/10.1017/S0267190504000054

Levis, J. (2007). Computer technology in teaching and researching pronunciation. Annual Review of Applied Linguistics, 27, 184-202. https://doi.org/10.1017/S0267190508070098

Ma, W., Zhou, P., Singh, L., \& Gao, L. (2017). Spoken word recognition in young tone language learners: Age-dependent effects of segmental and suprasegmental variation. Cognition, 159, 139-155. https://doi.org/10.1016/j.cognition.2016.11.011

Mezirow, J. (2008). Lifelong Learning: Concepts and Contexts. In P. Sutherland \& J. Crowther (Eds.), An overview of transformative learning (pp. 24-38). London: Routledge.

Moon, J. A. (2009). A handbook of reflective and experiential learning: theory and practice. London: Routledge Falmer.

Moon, J. A. (2013). Reflection in Learning and Professional Development: Theory and Practice. London, New York: Taylor \& Francis. https://doi.org/10.4324/9780203822296

Mora, J. C., \& Valls - Ferrer, M. (2012). Oral fluency, accuracy, and complexity in formal instruction and study abroad learning contexts. TESOL Quarterly, 46, 610-641. https://doi.org/10.1002/tesq.34

Munro, M., \& Derwing, T. (2006). The functional load principle in ESL pronunciation instruction: An exploratory study. System, 34(4), 520-531. https://doi.org/10.1016/j.system.2006.09.004

Munro, M., \& Derwing, T. (2008). Segmental acquisition in adult ESL learners: A longitudinal study of vowel production. Language Learning. Language Learning, 58(3), 479-502. https://doi.org/10.1111/j.1467-9922.2008.00448.x

Offerman, H. M., \& Olson, D. J. (2016). Visual feedback and second language segmental production: The generalizability of pronunciation gains. System, 59, 45-60. https://doi.org/10.1016/j.system.2016.03.003

Park, J. Y., \& Son, J. B. (2011). Expression and connection : the integration of the reflective learning process and the writing process into social network sites. Journal of Online Learning and Teaching, 7(1), 170-178.

Pawar, M., \& Anscombe, B. (2014). Reflective Social Work Practice: Thinking, Doing and Being. Australia: Cambridge University Press. https://doi.org/10.1017/CBO9781107425989

Rau, D., Chang, A., \& Tarone, E. (2009). Think or Sink: Chinese Learners' Acquisition of the English Voiceless Interdental Fricative. Language Learning, 581-621. https://doi.org/10.1111/j.1467-9922.2009.00518.x

Richter, C., Simonenko, E., Sugibuchi, T., Spyratos, N., Babic, F., Wagner, J., ... Christophides, V. (2012). Mirroring Tools for Collaborative Analysis and Reflection. In A. Moen, A. I. Mørch \& S. Paavola (Eds.), Collaborative Knowledge Creation: Practices, Tools, Concepts (Vol. 7: Technology enhanced learning, pp. 117-140). Rotterdam: Sense Publishers. https://doi.org/10.1007/978-94-6209-004-0_7 
Rogers, R. R. (2001). Reflection in Higher Education: A Concept Analysis. Innovative Higher Education, 26(1), 37-57. https://doi.org/10.1023/A:1010986404527

Ryan, M., \& Ryan, M. (2013). Theorising a model for teaching and assessing reflective learning in higher education. Higher Education Research \& Development, 32(2), 244-257. https://doi.org/10.1080/07294360.2012.661704

Saito, H., \& Miwa, K. (2007). Construction of a learning environment supporting learners' reflection: A case of information seeking on the Web. Computers and Education, 49(2), 214-229. https://doi.org/10.1016/j.compedu.2005.07.001

Saito, K. (2018). Advanced Second Language Segmental and Suprasegmental Acquisition. In P. A. Malovrh \& A. G. Benati (Eds.), The Handbook of Advanced Proficiency in Second Language Acquisition. New York John: Wiley Blackwell. https://doi.org/10.1002/9781119261650.ch15

Schmid, E. C. (2011). Video-stimulated reflection as a professional development tool in interactive whiteboard research. ReCALL, 23, 252-270. https://doi.org/10.1017/S0958344011000176

Sugerman, D. A. (2000). Reflective Learning: Theory and Practice. Kendall/Hunt Publishing Company.

Szpyra, J. (2014). Pronunciation in EFL Instruction. Bristol: Multilingual Matters. https://doi.org/10.21832/9781783092628

Tarrant, P. (2013). Reflective practice and professional development. London: Sage. https://doi.org/10.4135/9781526402318

Towell, R., Hawkins, R., \& Bazergui, N. (1996). The development of fluency in advanced learners of French. Applied Linguistics, 17, 84-119. https://doi.org/10.1093/applin/17.1.84

Van den Boom, G., Paas, F., van Merriënboer, J. J. G., \& van Gog, T. (2004). Reflection prompts and tutor feedback in a web-based learning environment: effects on students' self-regulated learning competence. Computers in Human Behavior, 20(4), 551-567. https://doi.org/10.1016/j.chb.2003.10.001

Van Zeeland, H., \& Schmitt, N. (2012). Lexical coverage in L1 and L2 listening comprehension: The same or different from reading comprehension? Applied Linguistics, 34, 457-479. https://doi.org/10.1093/applin/ams074

Veenendaal, N. J., Groen, M. A., \& Verhoeven, L. T. W. (2016). The contribution of segmental and suprasegmental phonology to reading comprehension. Reading Research Quarterly, 51, 55-66. Doi.org/10.1002/rrq.127

Warisara, Y. (2013). Improving English Stress And Intonation Pronunciation Of The First Year Students Of Nakhon Ratchasima Rajabhat University Through An e-Learning. Procedia - Social and Behavioral Sciences, 91, 444-452. https://doi.org/10.1016/j.sbspro.2013.08.442

Wu, X., \& Saito, K. (2013). Difficulty in the acquisition of Mandarin high level and high falling tones by Cantonese learners. The Journal of the Acoustical Society of America, 134(5), 4106. https://doi.org/10.1121/1.4831072

Xie, Y., Ke, F., \& Sharma, P. (2008). The effect of peer feedback for blogging on college students' reflective learning processes. The Internet and Higher Education, 11(1), 18-25. https://doi.org/10.1016/j.iheduc.2007.11.001

Yang, Y.-F. (2010). Students' reflection on online self-correction and peer review to improve writing. Computers \& Education, 55(3), 1202-1210. https://doi.org/10.1016/j.compedu.2010.05.017

Yenkimaleki, M., \& Van Heuven, V. J. (2018). The effect of teaching prosody awareness on interpreting performance: an experimental study of consecutive interpreting from English into Farsi. Perspectives, 26(1), 84-99. https://doi.org/10.1080/0907676X.2017.1315824

Yenkimaleki, M., \& Van Heuven, V. J. (2019). The relative contribution of computer assisted prosody training vs. instructor based prosody teaching in developing speaking skills by interpreter trainees: An experimental study. Speech Communication, 107, 48-57. https://doi.org/10.1016/j.specom.2019.01.006 


\section{Appendix A}

\section{Layout of a sample of the content of reflective videos}

\begin{tabular}{l}
\hline Reflection level \\
\hline - Analysis, \\
reformulation and \\
future application: \\
students explain how \\
their online experience \\
is connected to learning \\
segmental and \\
suprasegmentals:
\end{tabular}

\section{Script}

Example, 'I joined an online English phonetics course and I enjoy it as it is not only teaching me the correct English pronunciation, but also teaching me reflection. Our instructor has taught us the importance of using segmental and suprasegmentals features in speaking and how to use them. We have learned the major segmental including vowels, consonants, diphthongs and minor segmentals including the way of articulation. In addition, we have learned the use of suprasegmentals in English speech such as intonation, stress, and syllable.

For example, 'my instructor asked me to prepare reflective videos in which I apply the correct use of segmental and suprasegmentals while I speak. And my instructor's role is to listen to my speaking and give me his feedback in order to improve myself' For example, “After preparing my reflective vide, I received my peers' feedback for improving my pronunciation. Furthermore, I received my teachers' feedback concerning the following: 1 ) the way of

$$
\text { articulation of the sounds } / \theta / / / \mathbf{S} / \text { at }
$$

the initial sounds of some words. The instructor and my classmates suggested that I should follow this way: "the tongue should touch the front teeth in

\section{$/ \theta / /$ and this is called 'interdental'. While}

/s/ sound should be pronounced in this way: "the central position of the tongue is lower than the sides, forming a central groove for the air-flow."
Images + text on screen

-Image of the name of phonetics course on the screen

-Images of segmental symbols

$$
\begin{aligned}
& / \mathbf{u}, / \mathrm{d}, / \theta /, / \mathrm{w} / \mathrm{d} / \\
& /[\mathrm{w}, / \mathrm{si}, / \mathrm{tu} / \mathrm{f}, / \mathrm{e} /, / \mathrm{N} \\
& |\mathrm{au} /,| \mathrm{aI} /,|\mathrm{OU} /,| \mathrm{JI} /, \mid \mathrm{eI} /
\end{aligned}
$$

-images of (the way of articulation).

Images + texts of the suprasegmentals patterns (e.g., division of syllables, intonation)

-The text on the screen

-Images that express speaking and reflection

-Images of the way of articulating $/ \theta / /$ /

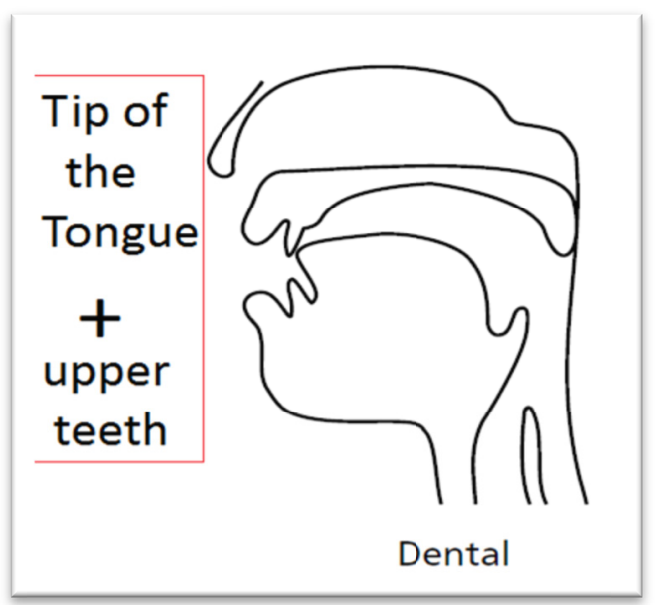

Images of the way of articulating /s/

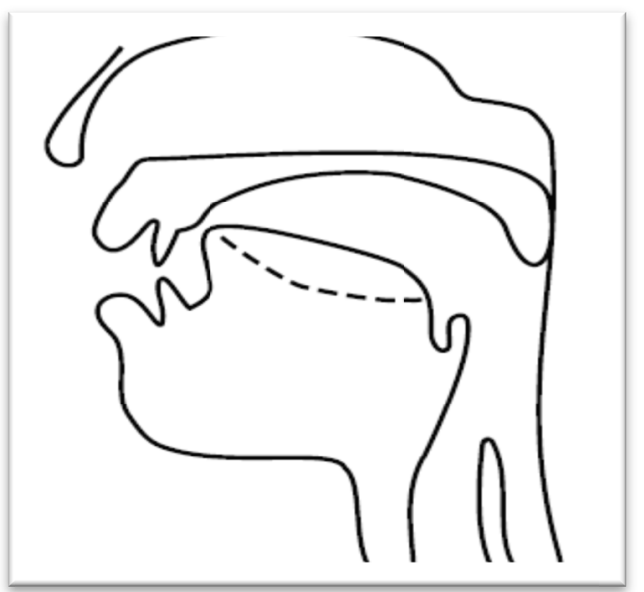


$\ln / s /$, the central portion

of the tongue, shown by

the dotted line, is lower

than the sides, forming

a groove from front to back

- $\quad$ Report of events or experiences: student reports significant aspects of the experience of online learning and identify the knowledge and skills gained from the experience
For example, 'I learned from the online course that when I speak, I should consider the correct use of segmental and suprasegmentals features. Moreover, I should be aware of the way of sound articulation and the cases in which I use correct suprasegmentals features (intonation, stress).
Fall (usually suggests a "inal" or "definite" "Eeeling)

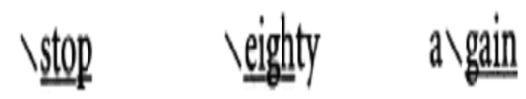

Rise (often suggesting a question)

/ sure / really to/night

Fall-rise (often suggesting uncertainty or hesitation) vome

Fall-rise is sometimes used instead of rise in giving lists Rise-alll (otten sounds surppisised or impressed) sob Novely inmmense

\section{Appendix B}

\section{Segmental test}

Total score...../40

A-Choose the words or the sentence you will hear (20 marks)
1) (A) Thank
(B) Sank
2) (A) glade
(B) grade
3) (A) face
(B) faith
4) (A) claim
(B) blame
5) (A) clock
(B) block
6) (A) feet
(B) heat
7) (A) mouse
(B) mouth
8) (A) hurt
(B) heart 

9) (A) path
(B) pass
10) (A) fold
(B) hold
11) (A) play
(B) pray
12) (A) sit
(B) seat
13) (A) hear
(B) heal
14) (A) live
(B) leave
15) (A) coat
(B) caught
16) (A) They are taking a boat.
(B) They are taking a goat
17) (A) Do not walk on the grass
(B) Do not walk on the glass
18) (A)Which girl is Don?
(B) Which girl is Done?
19) (A) The car could not pull them?
(B) The car could not pool them?
20) (A) The girl has lost her luck
(B) The girl has lost her lock

\section{$B$. Read the following words}

1) blend 2) click 3) crab 4) dream 5) frozen 6) glue 7) war 8) heat

9) right 10) hot 11) smart 12) think 13) sleeve 14) hole 15) see 16) feet 17) beat 18) grass 19) trail 20) sweat

\section{Appendix C}

\section{Suprasegmental test}

Total score...../40

A. Listen and underline the stressed syllables (10 marks)

1)politician 2) Japanese 3) industrial 4) reputation 5) fantastic 6) Memorial

7) psychology 8) assumption 8) volunteer 9) Canadian 10) heating

B. Read the following conversation (10 marks)

Mrs. Helen: come in, Patrik. How are you?

Patrik: Fine, Mrs. Helen. I'd like to ask you about an important thing and you've to answer it frankly, haven't you?

Mrs. Helen: Yes, of course. I'll try.

Patrik: How's my pronunciation of English? I've studied hard in your phonetics course, but still feel that I want more practice

Mrs. Helen: I think you've a lot to do for self-improvement.

Patrick: self-improvement? But do I pronounce English like a native speaker?

Mrs.Helen: Not exactly. But you'll someday.

C. Write the missing words of contraction and reductions you will hear (4 marks)

1) He............go

2) She................going

3) I .........................go shopping

4) He .................. get his car started.

5) She................be coming tomorrow.

6) How...............you been here?

7) What.....................done?

8) I am ........................... visit Japan next month.

D. Listen and write which of these sentences have a rising intonation or falling intonation or rising and falling intonation (10 marks) 
1) Did you remember to buy the milk?.

2) Where did you buy that?

3) Did she go to Italy or France last year?

4) Where do you live?

5) Where is the nearest bank, please?

6) Nice weather, isn't it?

7) Have you read this book?

8) Do you want coffee or tea?

9) She speaks English, doesn't she?

10) Have you seen my/glasses?

E. Read the following words according to their kind. (6 marks)

1) "Use" (a noun)

2) "Use" (a verb)

3) "Prove" (verb)

4) "Proof" (noun)

5) "Loose" (adjective)

6) "Lose" (verb)

\section{Appendix D}

\section{Suprasegmental Rubric}

\begin{tabular}{|c|c|c|c|c|c|}
\hline $\begin{array}{l}\text { Suprasegmental } \\
\text { Features }\end{array}$ & $\begin{array}{l}\text { Excellent } \\
4 \\
\end{array}$ & $\begin{array}{l}\text { Good } \\
3 \\
\end{array}$ & $\begin{array}{l}\text { Fair } \\
2 \\
\end{array}$ & $\begin{array}{l}\text { Poor } \\
1 \\
\end{array}$ & Score \\
\hline Intonation & $\begin{array}{l}\text { Good use of } \\
\text { intonation makes } \\
\text { the listener very } \\
\text { easy to follow. } \\
\text { Intelligibility of } \\
\text { meaning is very } \\
\text { high }\end{array}$ & $\begin{array}{l}\text { Adequate use of } \\
\text { intonation makes } \\
\text { the listener fairly } \\
\text { easy to follow, the } \\
\text { intelligibility of the } \\
\text { meaning and } \\
\text { message fairly high, } \\
\text { although there are } \\
\text { occasional lapses. }\end{array}$ & $\begin{array}{l}\text { Inadequate use of } \\
\text { intonation makes } \\
\text { the listener very } \\
\text { difficult to follow } \\
\text { the message. }\end{array}$ & $\begin{array}{l}\text { Flat intonation makes } \\
\text { the listener almost } \\
\text { impossible to } \\
\text { understand. }\end{array}$ & \\
\hline Stress & $\begin{array}{l}\text { Good use of stress } \\
\text { makes speech more } \\
\text { meaningful and } \\
\text { effective } \\
\text {-The speaker } \\
\text { making the right } \\
\text { syllables prominent. }\end{array}$ & $\begin{array}{l}\text { Adequate use of } \\
\text { stress. Intelligibility } \\
\text { is sometimes } \\
\text { impeded by making } \\
\text { the wrong syllables } \\
\text { prominent. }\end{array}$ & $\begin{array}{l}\text { Inadequate use of } \\
\text { stress. There is little } \\
\text { effort to make } \\
\text { syllables prominent } \\
\text { for facilitating the } \\
\text { Intelligibility. }\end{array}$ & $\begin{array}{l}\text { Flat syllabic stress } \\
\text { makes the speaker } \\
\text { almost impossible to } \\
\text { understand. There } \\
\text { is no attempt to make } \\
\text { syllabic stress in the } \\
\text { words prominent. }\end{array}$ & \\
\hline
\end{tabular}




\section{Segmental Features Rubric}

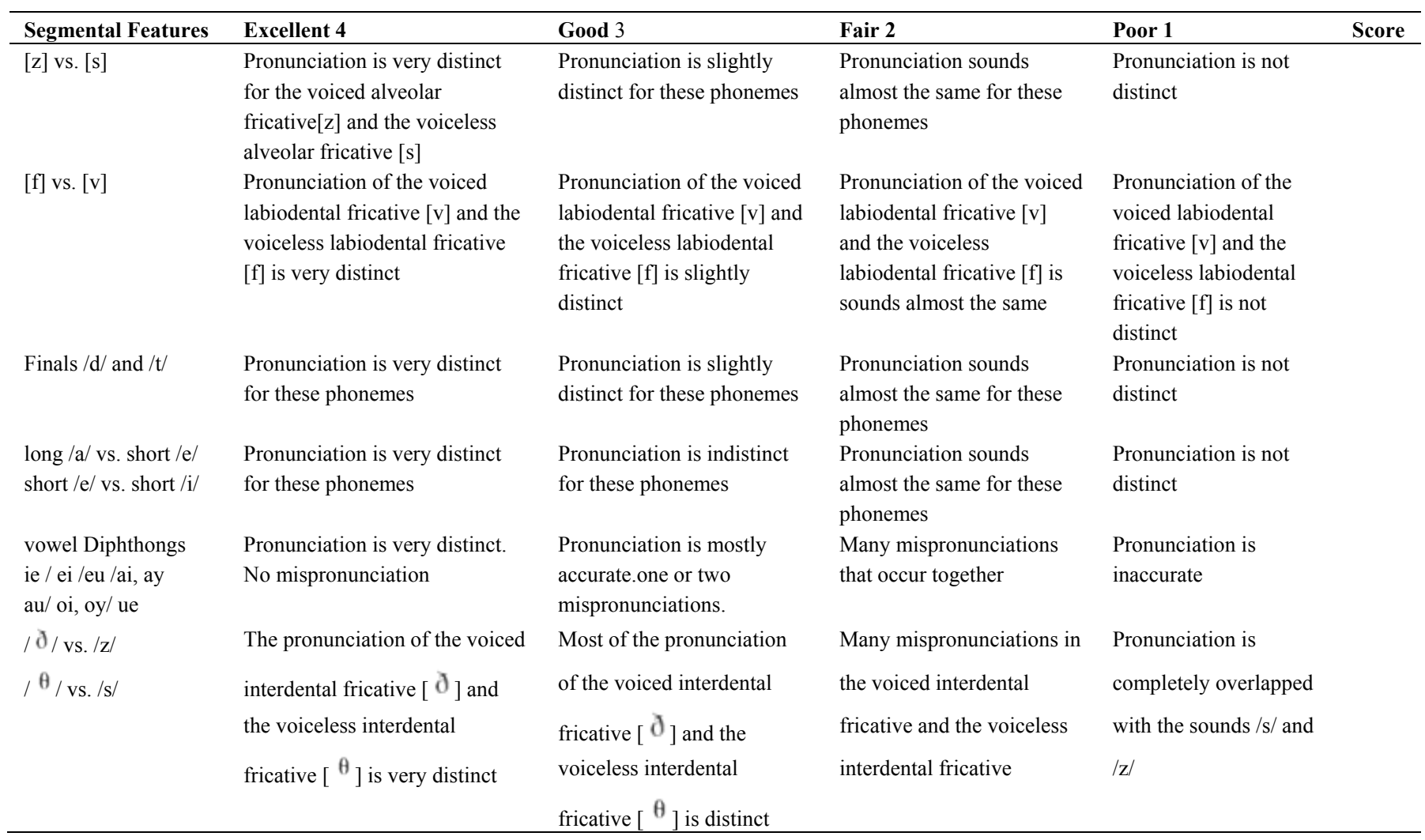

\section{Appendix E}

\section{Questionnaire}

1) To what extent do you agree that the online collaborative reflection could help you improve your English Learning?

2) To what extent do you agree that the online collaborative reflection could help you improve your use of segmental features of English speech?

3) To what extent do you agree that the online collaborative reflection could help you improve your use of suprasegmental features of English speech?

4) To what extent do you agree that the online collaborative reflection developed your reflective learning?

5) To what extent do you agree that the online instruction could facilitate your collaborative reflection? 


\section{Appendix F}

Results of students' responses on online questionnaire

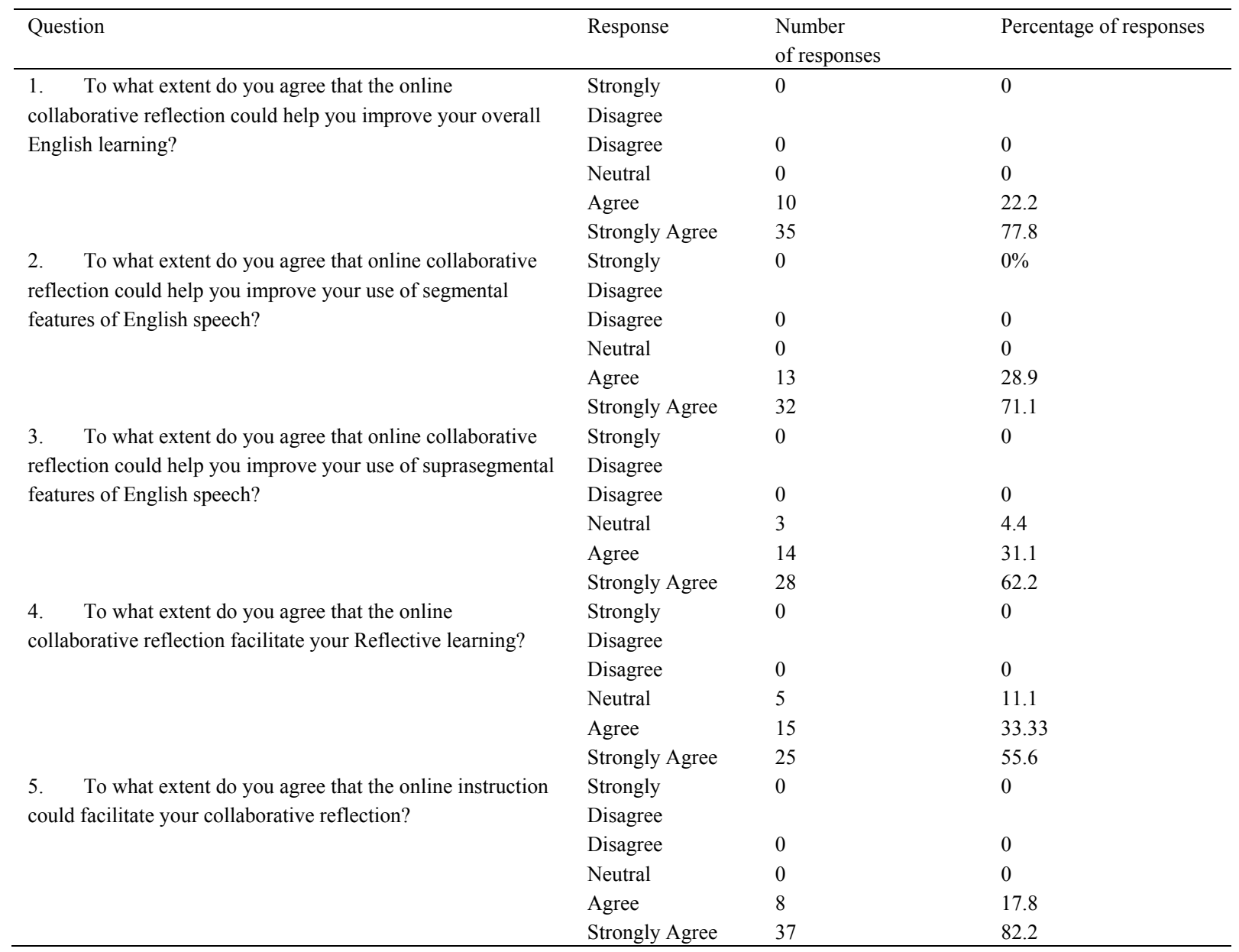

\section{How to cite this article:}

Abdelrahim, A. (2020). Improving Speaker's Use of Segmental and Suprasegmental Features of L2 Speech. International Journal of English Linguistics, 10(5), 203-220. https://doi.org/10.5539/ijel.v10n5p203

\section{Copyrights}

Copyright for this article is retained by the author, with first publication rights granted to the journal.

This is an open-access article distributed under the terms and conditions of the Creative Commons Attribution license (http://creativecommons.org/licenses/by/4.0/). 